J. Clin. Chem. Clin. Biochem.

Vol. 17, 1979, pp. 679-682

\title{
Referenzwerte für Kreatinin im Serum, ermittelt mit einer spezifischen enzymatischen Methode
}

\author{
Von U. Börner, G. Szász†
}

Institut für Klinische Chemie, Universitätskliniken Giessen,

\section{W. Bablok}

Boehringer Mannheim GmbH, Abteilung für Biometrie, Mannheim

und E. W. Busch

Boehringer Mannheim GmbH, Erprobung Diagnostica, Mannheim

(Eingegangen am 16. August/8. Oktober 1979)

Zusammenfassung: Für eine spezifische enzymatische Methode zur Bestimmung von Kreatinin im Serum, adaptiert auf ein diskontinuierliches Analysengerät, wurden Referenzwerte ermittelt.

Das Referenzkollektiv bestand aus 250 Frauen und 215 Männern, welches sich aus Blutspendern, Klinikpersonal und Patienten im Alter von 18-70 Jahren zusammensetzte.

Eine Abhängigkeit der Kreatininwerte vom Alter konnte in den Gruppen von 20-60 Jahren nicht festgestellt werden, jedoch bestand ein signifikanter Unterschied zwischen den Werten der Frauen und Männer. Als Referenzwerte für die "wahre" Kreatininkonzentration im Serum (95\% Bereich) empfehlen wir 44-80 $\mu \mathrm{mol} / 1$ für Frauen und 44-97 $\mu \mathrm{mol} / 1$ für Männer.

\section{A specific fully enzymatic method for creatinine: Reference values in serum}

Summary: Reference values for creatinine in serum were established using a fully enzymatic method, adapted to a discontinuous analyzer. Our reference group included 250 females and 215 males (blood donors, hospital staff and patients) aged $18-70$ years.

Up to 60 years, creatinine concentration did not depend on age, but there was a significant difference between the creatinine concentrations of women and men.

We propose reference ranges for creatinine in serum (95\% range) of 44-80 $\mu \mathrm{mol} / \mathrm{l}$ for women and of $44-97 \mu \mathrm{mol} / \mathrm{l}$ for men.

\section{Einführung}

Wahlefeld et al. (1) beschrieben eine enzymatische Methode zur spezifischen Bestimmung von Kreatinin in Serum, Plasma und Urin.

Referenzwerte für Kreatinin in Serum und Plasma wurden bisher nur mit verschiedenstẹn Modifikationen der unspezifischen Jaffé-Reaktion ermittelt (2). Die vorliegende Arbeit beschreibt die Ermittlung von Referenz̄werten für Kreatinin in Serum mit der spezifischen enzymatischen Methode an einem Kollektiv, bei dem versucht wurde, Nierenerkrạnkungen, soweit wie möglịch, auszuschließen. Zu Vergleichszwecken wurden noch żwei Modifikationen der Jaffé-Methode mitgefụhrt:

\section{Methoden}

Die enzymatische Methode wurde auf einen Eppendorf-SubstratAutomaten $5032^{1}$ ) adaptiert. (Pipettierschema: Abb. 1). Die Kreatininase-Suspension wurde mit $500 \mathrm{ml} / 1$ Glycerin im Verhält-

1) Hersteller: Netheler \& Hinz, Hamburg, Bundesrepublik Deutschland. 


\begin{tabular}{l|l|l}
\hline $\begin{array}{l}\text { Serum/Standard } \\
\text { Reagenziengemisch }\end{array}$ & $\begin{array}{c}\text { Probe } \\
100 \mu \mathrm{l} \\
500 \mu \mathrm{l}\end{array}$ & $\begin{array}{l}\text { Probenleerwert } \\
100 \mu \mathrm{l} \\
500 \mu \mathrm{l}\end{array}$ \\
\hline \begin{tabular}{l} 
Vorinkubation: $5 \mathrm{~min}$ bei $37^{\circ} \mathrm{C}$ \\
\hline Kreatininamidohydrolase
\end{tabular} & $-20 \mu \mathrm{l}$ & - \\
Glycerin ( $500 \mathrm{ml} / \mathrm{l})$
\end{tabular}

Abb. 1. Pipettierschema der enzymatischen Kreatinin-Bestimmung

nis 1:2 verdünnt, um auf ein für das Gerät unproblematisches Pipettiervolumen von $20 \mu \mathrm{l}$ zu kommen. Da die Reaktion nach 15 Minuten noch nicht vollständig abgelaufen ist, wurde die Konzentration über einen mitgeführten Standard ${ }^{3}$ ) bestimmt.

Auf einem SMA $6 / 60^{2}$ ) wurde die Jaffé-Reaktion nach Vorschrift und mit Reagenzien des Herstellers durchgeführt.

Die kinetische Jaffé-Methode nach Bartels (3) wurde auf einem Eppendorf-Enzym-Automaten $5020^{1}$ ) nach Vorschrift des Geräteherstellers durchgeführt. Als Standard dienten $20 \mathrm{mg} / 1 \mathrm{Kreatinin}^{3}$ ) in $50 \mathrm{~g} / 1$ Human-Albumin-Lösung. Angaben über Präzision, Linearität und weitere analytische Daten zu den einzelnen Methoden finden sich an anderer Stelle (4).

\section{Referenzkollektiv}

Obwohl versucht wurde, das Kollektiv möglichst auf gesunde Blutspender zu beschränken, waren wir, besonders bei den höheren Altersgruppen, gezwungen, auch Klinikpersonal und Patienten mit einzubeziehen. Die in das Kollektiv aufgenommenen Patienten kamen von der Neurochirurgischen und Gynäkologischen Universitätsklinik in Gießen.

Tabelle 1 gibt Aufschluß über die Kriterien, die zu einer Eliminirung der Probanden aus dem Referenzkollektiv führten. Inwieweit mit diesen Kriterien alle nierenkranken Personen ausgeschlossen werden konnten, läßt sich naturgemäß nicht mit letzter Sicherheit beantworten.

Tabelle 2 gibt die Zusammensetzung und Altersverteilung des Referenzkollektivs wieder. Die Zahlen in Klammern beziffern die wegen einer möglichen Nierenschädigung ausgeschiedenen Probanden.

\section{Probengewinnung}

Von allen Probanden wurden $20 \mathrm{ml}$ Blut nach vorheriger Stauung des Armes auf $60 \mathrm{~mm} \mathrm{Hg}$ aus der Kubitalvene entnommen. Das abzentrifugierte Serum wurde geteilt. Aus einer Portion wurden innerhalb von vier Stunden mit dem SMA 6/60 die Konzentrationen von Kreatinin, Harnstoff und Harnsäure bestimmt. Die andere Portion zur Ermittlung der Werte der enzymatischen Kreatinin-Bestimmung wurde bei $-20^{\circ} \mathrm{C}$ eingefroren. Die Urinproben der Probanden wurden nach der Blutentnahme gewonnen und innerhalb von vier Stunden analysiert.

Die tiefgefrorenen Seren wurden später in an einem Tag zu verarbeitende Mengen aufgetaut und die enzymatischen Kreatinin-Werte in Doppelbestimmungen ermittelt.

\section{Statistische Verfahren}

Die statistische Auswertung wurde mit parameterfreien Verfahren durchgeführt; alle Aussagen wurden mit einer Irrtumswahrscheinlichkeit von $\alpha=0,05$ getroffen.

2) Hersteller: Technicon, Tarrytown, N.Y. USA

$\left.{ }^{3}\right)$ Substanz: Standard Reference Material 914 Creatinine vom National Bureau of Standards, Washington, D.C., USA
Tab. 1. Ausschlußkriterien aus dem Referenzkollektiv, erhoben aus dem persönlichen Fragebogen.

a) Blutdruck: Systolisch $>160 \mathrm{~mm} \mathrm{Hg}$ und diastolisch $>95 \mathrm{~mm} \mathrm{Hg}$ (W H O)

b) Gegenwärtige oder frühere Erkrankungen: Hypertonie Herzinsuffizienz Nierenerkiankungen Diabetes Gicht/Hyperurikämie neoplastische Erkrankungen

c) Urinanalyse:

$\begin{array}{ll}\text { Protein } & \text { ) } \\ \text { Glucose } & \text { ) } \\ \text { Urobilinogen } & \text { ) jedes positive Resultat } \\ \text { Bilirubin } & \text { ) jel } \\ \text { Nitrit } & \text { ) } \\ \text { Blut } & \\ \text { Hämoglobin } & \text { ) }\end{array}$

d) Urinsediment: Pathologische Zellarten und -zahlen

e) Harnstoff im Serum: > als $8,33 \mathrm{mmol} / \mathrm{l}$

f) Harnsäure im Serum: > als $417 \mu \mathrm{mol} / \mathrm{l}$ (Männer)

$>$ als $357 \mu \mathrm{mol} / 1$ (Frauen)

Angewandte Tests

Mit dem U-Test nach Mann \& Withney wurde auf Unterschiede in der Kreatininkonzentration bei Männern und Frauen geprüft (5).

Mit einem Verfahren von Wilcoxon wurde untersucht, ob zwischen den Referenzbereichen der drei Methoden Unterschiede bestehen (6).

Die Altersabhängigkeit der Kreatininkonzentrationen wurde mit dem Spearman'schen Korrelationskoeffizienten überprüft (5).

\section{Ergebnisse und Diskussion}

Wie aus Tabelle 2 zu ersehen ist, wurden bei den Männern 44 und bei den Frauen 77 Probanden aus dem Referenzkollektiv eliminiert. Bei den Männern überwiegt in den unteren Altersgruppen die Diagnose einer Hyperurikämie, bei den Frauen die Diagnose eines Harnwegsinfektes, die in der überwiegenden Mehrzahl der Fälle aus einem pathologischen Urinbefund abgeleitet werden konnte. Die übrigen Diagnosen sind bei beiden Geschlechtern etwa gleich häufig (Tab. 3). Bei den älteren Männern und Frauen nimmt die Zahl derer, die aus anamnestischen Gründen ausgeschieden wurden, $\mathrm{zu}$. In Tabelle 4 sind die $95 \%$ Bereiche (2,5.-97,5. Percentil) der Kreatinin-Werte des selektierten Referenzkollektivs dargestellt, zur Ermittlung wurde von nicht klassifizierten Daten ausgegangen. Die Zahlen zeigen, daß sich beim Median für die enzymatische und für die kinetische Methode die Werte nur geringfügig ändern, während beim 97,5. Percentil, besonders für die Frauen, ein Trend zu niedrigeren Werten. deutlich wird. Der Unterschied zwischen den Werten von Männern und Frauen war signifikant. Gegenüber den beiden Modifikationen der Jaffé-Methode wurden, wie zu erwarten war, mit der enzymatischen Methode niedrigere Werte gefunden. besonders ausgeprägt ist dies gegenüber der AutoAnalyzer-Methode. Unsere Ergebnisse 
Tab. 2. Zusammensetzung und Altersverteilung der Referenzgruppen

\begin{tabular}{llllll}
\hline & Männer & Frauen & & & \\
Blutspender & $133(23)$ & $90(11)$ & & \\
Patienten & $62(17)$ & $129(56)$ & & & \\
Klinikpersonal & $20(4)$ & $31(10)$ & & & \\
lnsgesamt & $215(44)$ & $250(77)$ & & & \\
& $18-29$ Jahre & $30-39$ Jahre & $40-49$ Jahre & $50-59$ Jahre & Über 60 Jahre \\
Männer & $47(7)$ & $43(10)$ & $50(7)$ & $49(7)$ & $26(13)$ \\
Frauen & $50(4)$ & $50(12)$ & $56(16)$ & $62(19)$ & $32(26)$ \\
\hline
\end{tabular}

Tab. 3. Aufgliederung der Ausschlußkriterien aus dem Referenzkollektiv

\begin{tabular}{|c|c|c|c|c|c|c|c|c|c|c|c|c|}
\hline \multirow[t]{2}{*}{ Alter, Jahre } & \multicolumn{2}{|c|}{$18-29$} & \multicolumn{2}{|c|}{$30-39$} & \multicolumn{2}{|c|}{$40-49$} & \multicolumn{2}{|c|}{$50-59$} & \multicolumn{2}{|c|}{ über 60} & \multicolumn{2}{|c|}{ Gesamt } \\
\hline & $\delta$ & 9 & $\delta$ & 9 & $\delta$ & 8 & $\delta$ & $?$ & $\delta$ & ? & $\delta$ & 9 \\
\hline Hyperurikämie & 5 & 1 & 9 & - & 4 & 1 & - & - & 2 & 2 & 20 & 4 \\
\hline Urämie & - & - & - & - & 1 & 1 & 1 & 4 & 5 & 7 & 7 & 12 \\
\hline Hypertonie & 2 & 2 & 2 & - & - & 3 & 2 & 4 & 3 & 7 & 9 & 16 \\
\hline Urinanalytik & 1 & - & - & 1 & 1 & 8 & 2 & 7 & 5 & 6 & 9 & 22 \\
\hline Sediment & 1 & 2 & - & 9 & - & 10 & 3 & 12 & 3 & 12 & 7 & 45 \\
\hline Fragebogen & 1 & 1 & 2 & 10 & 5 & 19 & 6 & 25 & 17 & 42 & 31 & 97 \\
\hline $\begin{array}{l}\text { Gesamtzahl der eliminierten } \\
\text { Individuen }\end{array}$ & 7 & 4 & 10 & 12 & 7 & 16 & 7 & 19 & 13 & 26 & 44 & 77 \\
\hline
\end{tabular}

Tab. 4. Referenżwerte für Kreatinin im Serum (Werte in $\mu \mathrm{mol} / \mathrm{l}$ )

\begin{tabular}{llrrr}
\hline & & \multicolumn{3}{c}{ Perce n t ile } \\
& 2,5 & 50,0 & \multicolumn{1}{c}{97,5} \\
\hline & Enzymatisch & 48,62 & 71,61 & 97,24 \\
Männer (n=171) Kinetisch & 50,39 & 78,68 & 99,89 \\
& SMA 6/60 & 70,72 & 88,40 & 106,08 \\
Frauen (n=173) & Enzymatisch & 41,55 & 58,35 & 80,45 \\
& Kinetisch & 53,93 & 68,95 & 90,17 \\
& SMA 6/60 & 53,04 & 70,72 & 97,24 \\
\hline
\end{tabular}

mit der kinetischen und der AutoAnalyzer-Methode stimmen recht gut mit Werten aus der Literatur überein (2).

Eine Altersabhängigkeit der Kreatinin-Werte konnte in den Altersgruppen bis $59 \mathrm{~J}$ ahre nicht festgestellt werden, die Gruppe der über 60-jährigen Probanden war so schwach besetzt, daß sie zur statistischen Beurteilung der Altersabhängigkeit der Kreatinin-Werțe nicht mít einbezogen wurde. Abbildung 2 zeigt hierzu die Lage der Mediane in den einzelnen Altersgruppen von Männern und Frauen.

Wir empfehlen daher die Benutzung der vollenzymatischen Methode zur Kreätinin-Bestimmung und möchten als Rëferenżbereiche für Kreatinin im Serưm für Frauen 44-80 $\mu \mathrm{mol} / \mathrm{l}$ und für Männer 44-97 $\mu \mathrm{mol} / 1$ vorschlagen.

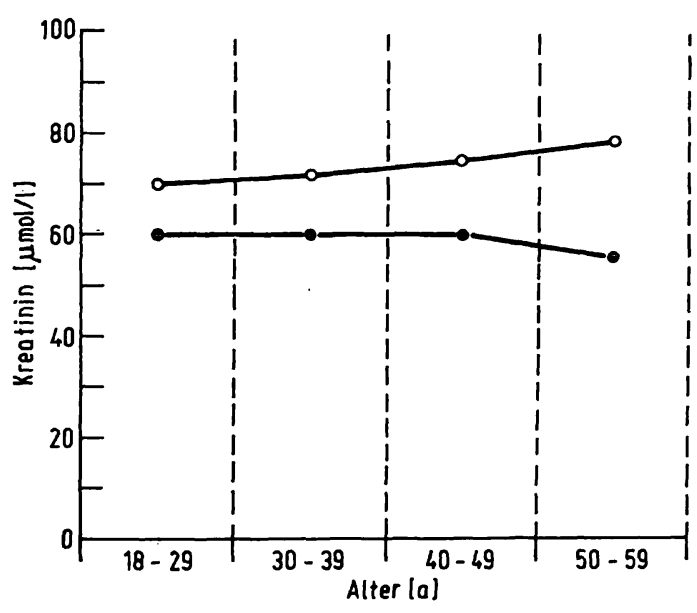

Abb. 2. Altersabhängigkeit der Kreatininwerte Mediane der Kreatininkonzentrationen in den einzelnen Altersgruppen ○—— Männer; •— Frauen

\section{Danksagung}

Wir danken Frau Christiane Häuser, Frau Gabi Richtberg und vor allem Herrn Albert Brüstle für die ausgezeichnete technische Unterstützung. 


\section{Literatur}

1. Wahlefeld, A. W., Herz, G. \& Bergmeyer, H. U. (1972) Scand. J. Clin. Lab. Inv. 29, Suppl. 126, abstract 30.1

2. Richterich, R. \& Colombo, J. P. (1978), Klinische Chemie, 4. Auflage, S. 554, S. Karger, Basel, München, Pạris, London, New York, Sydney.

3. Bartels, H., Böhmer, M. \& Heierli, C. (1972) Clin. Chim. Acța 37, 193-197.
4. Szász, G., Börner, U., Busc̄h, E. W. \& Bablok, W. (1979), J. Clin. Chem. Clin. Biochem. 17, 683-687.

5. Conover, W. J. (1971), Practical Nonparametric Statistics, John Wiley \& Sons: New York, p. 224, p. 251.

6. Wilcoxon, F. \& Wilcox, R: (1964), Some rapid approximate statistical procedures, Lederle Lab., Pearl River, N.Y., p. 11

W. Bablok

Boehringer Mannheim GmbH

Abteilung für Biometrie

Sandhofer Straße 116

D-6800 Mannheim 31 